\title{
PENA FEMININA: A CRÔNICA DE ADÍLIA DE ALBUQUERQUE NA IMPRENSA CEARENSE DO INÍCIO DO SÉCULO XX
}

\author{
CASTRO, Carla Pereira de ${ }^{1}$
}

RESUMO: A participação na imprensa cearense do final do século XIX e do início do século XX era praticamente restrita aos intelectuais do sexo masculino que, ao longo dos anos, demarcaram seus espaços amparados pela cultura do patriarcalismo, na qual as mulheres deveriam se dedicar somente aos cuidados com o marido e o lar. Poucas foram as mulheres que ousaram ingressar nessa seara. No século XIX tivemos a participação de Francisca Clotilde e de Anna Nogueira Baptista na Padaria Espiritual e no Club Literário. No século XX, outras mulheres também ousaram escrever e a publicar, as irmãs Amélia de Alencar e Olga de Alencar editaram o seu próprio jornal $O$ Astro ainda em 1902. Adília de Albuquerque também fez parte desse cenário, escrevendo crônicas para diversos jornais, dentre eles o Ceará Ilustrado, A Razão e O Povo. Entretanto poucas são as informações sobre a escritora. Nesse artigo pretendemos resgatar a participação de Adília de Albuquerque na literatura de autoria feminina cearense, corrigir dados sobre a sua biografia e apresentar textos de sua autoria publicados na década de 20. Para fundamentar nossas pesquisas utilizaremos os estudos de Constância Lima Duarte e Hélène Cixous, que analisam a literatura de autoria feminina.

PALAVRAS-CHAVE: Adília de Albuquerque, Imprensa cearense, Século XX, Literatura de autoria feminina.

\section{PLUME FÉMININE : LA CHRONIQUE D’ADÍLIA DE ALBUQUERQUE DANS LA PRESSE DU CEARÁ AU DÉBUT DU $\mathrm{XX}^{\mathrm{E}}$ SIÈCLE}

\footnotetext{
${ }^{1}$ Mestranda do curso de Literatura Comparada da UFC - Universidade Federal do Ceará. Professora de Língua portuguesa no Estado do Ceará. professoracarlacastro@gmail.com
} 
RÉSUMÉ : La participation à la presse du Ceará à la fin du XIX ${ }^{\mathrm{e}}$ siècle et au début du $\mathrm{XX}^{\mathrm{e}}$ siècle était pratiquement limitée aux intellectuels masculins qui, au fil des ans, ont délimité leurs espaces soutenus par la culture du patriarcat où les femmes devraient se consacrer uniquement à prendre soin de leur mari et la maison. Peu de femmes ont osé entrer dans ce domaine. Au XIX ${ }^{\mathrm{e}}$ siècle, nous avons eu la participation de Francisca Clotilde et Anna Nogueira Baptista à Padaria Espiritual et au Club Literário. $\mathrm{Au} \mathrm{XX}^{\mathrm{e}}$ siècle, d'autres femmes ont également osé écrire et publier, les sœurs Amélia de Alencar et Olga de Alencar ont édité leur propre journal O Astro en 1902. Adília de Albuquerque faisait également partie de ce scénario, écrivant des chroniques pour plusieurs journaux, parmi lesquels le Ceará Ilustrado, A Razão et $O$ Povo. Cependant, il y a peu d'informations sur l'écrivain. Dans cet article, nous avons l'intention de récupérer la participation d'Adília de Albuquerque dans la littérature féminine du Ceará et de corriger les données sur sa biographie, en présentant ses propres textes publiés aux années 1920. Pour soutenir nos recherches, nous utiliserons les études de Constância Lima Duarte et Hélène Cixou, qui analysent la littérature écrite par des femmes

MOTS-CLÉS : Adília de Albuquerque, Presse Ceará, 20ième siècle, Littérature écrite par des femmes.

\section{INTRODUÇÃO}

A historiografia que aborda a participação da mulher na sociedade e nas letras ao longo da história da humanidade está sendo revista, tendo em vista que o seu apagamento e a sua invisibilidade não poderiam permanecer eternamente no silêncio. A pesquisadora Constância Lima Duarte nomeia esse apagamento com a terminologia memoricídio, que ao pé da letra significa a morte da memória ou o apagamento da memória. Em seu artigo "Arquivos de mulheres e mulheres anarquivadas: histórias de uma história mal contada", Duarte lembra que no clássico estudo Um teto todo seu, de 1929, Virginia Woolf, ao visitar bibliotecas à procura de obras escritas por mulheres, e constatar o número quase insignificante dessa produção, atribuiu à profunda misoginia que não cansava de afirmar a inferioridade mental, moral e física do gênero feminino, as poucas chances que então eram dadas às mulheres. Felizmente Woolf não foi a única mulher, escritora, pesquisadora a constatar essa ausência, hoje somos muitas estudiosas que se dedicam ao resgate das escritoras silenciadas e invisibilizadas ao longo dos séculos. 
Para conceituar escrita feminina é preciso observar algumas acepções acerca do objeto. A escrita feminina é feita somente por mulheres? Para mulheres? Sobre as mulheres? Defende ideologias feministas? Para a pesquisadora Hèlène Cixou a escrita feminina denomina-se feminina quando o discurso para de ser centrado no homem.

Ao se utilizarem da escrita para expor os seus pensamentos e ideais as escritoras romperam com a dominação patriarcal da época produzindo discursos próprios onde defendiam seus ideais. O apagamento dos nomes de nossas escritoras não se justifica, dada a importância de suas atuações nas agremiações literárias e suas contribuições na imprensa cearense do século XIX e início do século XX.

Para justificar a utilização da terminologia escrita feminina nos embasamos nos estudos de Lúcia Castello Branco e sua obra A Mulher Escrita (1989) e nos estudos do pesquisador Antônio de Pádua Dias da Silva em seu artigo A Diferença na autoria feminina contemporânea, publicado na obra Deslocamentos da Escritora Brasileira (2011).

Podemos dizer que temos, nesse momento, o princípio de uma escrita feminina, elementar e rude em suas bases, no sentido do não aperfeiçoamento da tecnologia da escrita literária, fato que percebemos hoje com as discussões ficcionais em torno das subjetividades femininas (antes havia uma espécie de busca por uma identidade universal). Essas subjetividades, naquele momento, final do século XIX e meados do século XX, não podiam ser pensadas, construídas, nem nas imagens nem através de uma linguagem particularizada, uma vez que estávamos vivendo os primeiros passos das mulheres que se lançavam como escritoras, bastante criticadas, reprimidas, motivos de pilhérias e piadas; daí um recuo e um resultado não sistemático na produção e, também na respectiva representação e desenvolvimento de um estilo e linguagem próprias. (GOMES \& ZOLIN, 2011, p. 235)

Como bem observa o pesquisador, no final do século XIX e início do século XX, no Brasil, as mulheres estavam ingressando na escrita literária, fundando periódicos para que pudessem publicar os seus textos e os seus poemas. Inserindo-se em agremiações literárias e reivindicando o direito e o acesso à educação.

A discussão sobre as terminologias escrita feminina e escrita de autoria feminina se justificam pelos deslocamentos vivenciados pelas autoras durante a passagem do século XIX para o século XX. Como evidenciamos, ainda no século XIX e início do século XX, as escritoras 
lutavam por suas inserções no universo literário, enquanto no decorrer do século XX e XXI suas lutas se destacavam pelas causas feministas e por lutas pela igualdade de direitos em relação aos homens. Dentre elas a visibilidade de seus textos e o questionamento da ausência dos seus nomes no cânone literário.

Para confirmar a ausência do registro do nome de escritoras cearenses nascidas no século XIX, nas obras que falam sobre a literatura cearense, tomamos como exemplo alguns livros consultados para o estudo.

Na obra O Ceará e os Cearenses (1906) de Antônio Bezerra de Meneses, o estudioso faz uma apresentação sobre a literatura feita por mulheres.

Depois do ensino doméstico, são em geral educadas com esmero nas letras e nas belas artes.

Há ali senhoras que tem nome feito como poetisas e escritoras.

São bem conhecidas as Exmas. Sras. Anna Nogueira, Francisca Clotilde, Ignácia de Matos Dias, Emilia de Freitas, Francisca de Mello Cezar, Luiza Amélia de Paula Rodrigues, Anna Lectícia da Frota Pessoa, Luiza Justa, Anna Facó, Anna Bilhar, Adília de Albuquerque Luna Freire, Maria Salazar, Maria Rodrigues, (Alba Valdez), Maria Amélia Torres Portugal, Aurelinda Simões, Olga de Alencar, Amélia de Alencar e Júlia Moura, estas seis últimas, directoras da Liga Feminista Cearense, fundada pelas mesmas em 26 de Julho de 1904, e muitas outras, que honram os jornais com os seus escritos.

Em música e desenho conhecemos também cultoras distintíssimas. (MENESES, 1906, p. 75)

Dentre os nomes citados, poucos são reconhecidos, de modo que destacamos o nome de Alba Valdez, a primeira mulher a ingressar na Academia Cearense de Letras, em 1922, e pioneira ao criar uma agremiação feminista, ainda em 1904 - a Liga Feminista Cearense. Poucos são os registros encontrados sobre o primeiro movimento feminista no Brasil, ocorrido em Fortaleza; de todas as obras pesquisadas, as únicas que mencionam o movimento são o já citado O Ceará e os Cearenses de Antônio Bezerra de Menezes e Ensaístas Brasileiras, de Heloisa Buarque de Hollanda \& Lúcia Nascimento Araújo. 
A primeira agremiação literária feminina de que se tem notícia foi a Liga feminista Cearense, fundada em 1904 por Alba Valdez, identificada no meio literário como defensora do direito da ascensão cultural, econômico e político para as mulheres.

Outra pioneira foi a Academia Juvenal Galeno, da escritora Júlia Galeno, que, tendo seu ingresso recusado na Academia Brasileira de Letras, cria sua própria academia "exclusivamente para mulheres", explicitando sua crítica frente à posição sexista da Academia Brasileira e promovendo sua inserção, ainda que marginal, no mundo institucionalizado das "belas-letras". (HOLLANDA, 1993, p. 23)

O Jornal do Ceará de 24 de junho de 1904, em sua segunda página, na coluna ECHOS E NOTICIAS, informa o nome de Adília de Lima Freire como participante do movimento literário feminino que estava para surgir na cidade de Fortaleza. Posteriormente não sabemos se Adília continuou a participar do movimento que foi intitulado como Liga Feminista Cearense, liderado por Alba Valdez.

Em Ceará Intellectual (1910) de Joaquim da Costa Nogueira, observamos um número expressivo de escritores: 18 homens e 6 mulheres. São elas: Adília de Luna Freire, Anna Facó, Francisca Clotilde, Francisca de M. Cesar Barcellos, Alba Valdez e Antonietta Clotilde.

Em Poetas Esquecidos (1938) do estudioso Mario Linhares, temos mais de vinte poetas e apenas três poetisas, Auta de Souza, Branca Bilhar e Carmen Cinira.

Acrescentamos o estudo de Mário Linhares, História Literária do Ceará de 1948, no qual estão retratados quase 200 escritores e apenas 12 mulheres, dentre elas: Ana Nogueira Batista, Diva Câmara, Francisca Clotilde, Maria Duarte, Emília de Freitas, as irmãs Galeno, as irmãs Sampaio, Ùrsula Garcia, Alba Valdez e Rachel de Queiroz. Diva Câmara, escritora e atriz, e Maria Duarte, poetisa, que viveu grande parte da sua vida no Rio de Janeiro, escrevendo para imprensa e participando da vida intelectual da cidade.

Augusto Linhares em sua Coletânea de Poetas Cearenses (1952) destaca mais de 80 autores homens e apenas 8 escritoras, são elas: Ana Nogueira Batista, Fernanda Brito, Francisca Clotilde, Henriqueta Galeno, Jandira Carvalho, Maria de Lourdes Vasconcelos Pinto, Stefania Rocha Bezerra e Úrsula Garcia.

Na obra Literatura Cearense (1976), do professor Sânzio de Azevedo, podemos verificar que foram estudados quase 200 escritores homens e apenas 5 mulheres, são elas: 
Cândida Galeno, Lúcia Fernandes Martins, Margarida Sabóia de Carvalho, Marly Vasconcelos e Rachel de Queiroz, autoras do século XX.

Através desse panorama podemos constatar que os pesquisadores em literatura, sobretudo a literatura cearense, priorizaram o estudo dos autores homens em detrimento dos estudos da autoria feminina, de modo que assim muitos nomes de escritoras ficaram apagados dos estudos literários.

Adília de Albuquerque nasceu no dia 12 de dezembro de 1874, na cidade de Icó, no interior do Ceará. Filha de Maria Leontina Coelho de Albuquerque e de José Pinto Coelho de Albuquerque, político de alto prestígio, deputado e presidente da Assembleia Legislativa do Ceará. Quando solteira, publicou na imprensa textos literários sob os nomes de Adília Coelho de Albuquerque e Adília Pinto Coelho de Albuquerque.

Adília de Albuquerque casou-me muito jovem com José Antônio de Luna Freire, filho de Adelino Antônio de Luna Freire e de Umbelina Augusta de Mello Luna. De acordo com o jornal Gazeta do Norte, de 13 de dezembro de 1886, o Sr. Bacharel Adelino Antônio de Luna Freire veio de Recife para o Ceará em companhia de sua família para assumir o cargo de Desembargador. O magistrado exerceu o cargo até se aposentar em 1890, conforme nota do periódico Cearense, de 30 de setembro de 1890. O Bacharel faleceu aos 84 anos no dia primeiro de março de 1913, no Recife, conforme foi noticiado no Diário de Pernambuco de 2 de março de 1913.

Não foi possível localizar a data do casamento de Adília de Albuquerque e José Antônio de Luna Freire. No jornal A República, de 16 de outubro de 1897, encontramos uma nota informando que o Sr. Coronel José Pinto Coelho havia partido para Granja com o intuito de visitar o genro, o ilustre dr. Bacharel José Antônio de Luna Freire, que na época exercia a função de Juiz de Direito da comarca de Granja desde 1895, conforme os relatórios dos Presidentes dos Estados brasileiros.

\section{PASSANDO A LIMPO}

Somente foi possível confirmar a informação do nome do marido de Adília de Albuquerque tendo acesso a Revista Escolar do Collegio Nogueira, Anno XII, No 131- Vol. XII, No. 3 de Setembro de 1926, editada pelo professor Joaquim da Costa Nogueira, na página 06, na seção Relembrando O Passado. 
FONTE: Revista Escolar do Collegio Nogueira, Anno XII, No 131- Vol. XII, No. 3 de Setembro de 1926, páginas 6

Tendo em vista que as referências sobre Adília de Albuquerque extraídas da obra Dicionário Bio-bibliográfico de mulheres ilustres, notáveis e intelectuais do Brasil $1^{o}$ volume de Adalzira Bittencourt afirmam que após casar-se com José Adelino de Lima Freire, adotou o nome Adília de Lima Freire. Diante dessa nota da Revista Escolar identificamos que José Adelino de Luna Freire era seu filho e não seu marido. E o sobrenome correto é Luna Freire e não Lima Freire.

Na obra Dicionário Mulheres do Brasil de 1500 até a atualidade biográfico e ilustrado, organizado por Schuma Schumaher e Érico Vital Brazil, também foi registrada de forma equivocada a informação de que Adília, após casar-se com José Adelino de Lima Freire, adotou o nome Adília de Lima Freire, informação já corrigida anteriormente.

Nasceu em 12 de dezembro de 1874, em Icó (CE), filha de Maria Leontina Coelho de Albuquerque e de José Pinto Coelho de Albuquerque, deputado e presidente da Assembléia Legislativa do Ceará.

Quando solteira, publicou na imprensa textos literários sob os nomes de Adília Coelho de Albuquerque e Adília Pinto Coelho de Albuquerque. Após casar-se com José Adelino de Lima Freire, adotou o nome Adília de Lima Freire. Casou-se pela segunda vez, com o escritor e advogado Tancredo de Moraes, quando então passou a assinar-se Adília de Albuquerque Moraes.

Formada pela Escola Normal de Fortaleza, aí ocupou, por concurso, a cadeira de português, tendo desempenhado, mais tarde, a função de inspetora federal de ensino. 
Defensora das idéias pautadas pelo feminismo, utilizou os jornais como um canal para divulgar, através de artigos, a campanha pela conquista dos direitos políticos e sociais da mulher. Representou o Ceará no I Congresso Internacional Feminista, realizado em 1922 no Rio de Janeiro pela Federação Brasileira pelo Progresso Feminino.

Participou de várias associações culturais do estado e, segundo o memorialista cearense Nirez, foi a partir de uma campanha de Adília, no início da década de 1930, que a principal praia de Fortaleza recebeu o nome de Iracema.

Faleceu no Rio de Janeiro em 2 de novembro de 1942. (SCHUMAHER, 2000, p. 24)

O casal Adília de Albuquerque de Luna Freire e José Antônio de Luna Freire teve três filhos, Orlando Ariosto de Luna Freire, Jose Adelino de Luna Freire e Maria Dolores de Luna Freire que depois de casada passou a assinar Maria Dolores Rocha Lima. José Antônio de Luna Freire faleceu no Ceará, no dia 25 de setembro de 1898, conforme nota do Jornal de Recife.

Adília ficou viúva prematuramente aos vinte e quatro anos quando resolveu voltar a estudar e trilhar uma trajetória diferente de tantas mulheres que se entregavam à tristeza da viuvez e viviam na dependência de parentes. Formou-se pela Escola Normal de Fortaleza e em 1899 passou a lecionar como professora adjunta na cadeira de classe infantil, tendo desempenhado, mais tarde, a função de inspetora federal do ensino.

Em 1910, casa-se com o jornalista e advogado Tancredo Moraese e passa a morar na Praia do Peixe, assumindo o sobrenome Adília de Albuquerque Moraes. O casal teve apenas uma filha, Berenice Moraes, que foi eleita miss Fortaleza em 1929. Representou o Ceará no I, II e no III Congresso Internacional Feminista, realizados no Rio de Janeiro pela Federação Brasileira pelo Progresso Feminino.

Pelo Decreto no 2.166 de 22 de setembro de 1924, Adília é aposentada como professora do curso anexo à Escola Normal. Após o qual participou de várias associações culturais do Estado e foi a partir de uma campanha de Adília, no início da década de 1930, que a principal praia de Fortaleza recebeu o nome de Iracema. Antes denominada Praia do Peixe.

Adília teve uma participação pioneira na política ao participar do Partido Liberal Evolucionista do Ceará, feito inédito para a época, sendo uma das cinco candidatas na disputa pelas eleições de 1934 para a Câmara Federal e a Assembleia Constituinte do Ceará, saindo 
derrotada, entretanto sua participação no pleito significou um avanço no processo eleitoral feminino. Publicou suas crônicas e artigos nos jornais A República, Correio do Ceará, Gazeta de Notícias, Unitário, O Estado, O Nordeste, A Razão, Ceará Ilustrado e O Povo. Deixou as seguintes obras: Crônicas da Escola Normal; História de Ceará e Lições de Português. A escritora faleceu no Rio de Janeiro em 2 de novembro de 1942.

No periódico Ceará Illustrado, de 7 de setembro de 1925, Adília publica a crônica $O$ Divórcio, onde questiona os deveres que são exigidos das mulheres por ocasião do matrimônio, e a impossibilidade do divórcio perante um casamento em que não há o amor e o respeito.

\section{O Divórcio}

\section{Ao Sr. Gilberto Camara}

Adília de Albuquerque

Cartas de mulher! - Cartas sem generalisação e falhas de synthese! Sois o reflexo, não de todas as almas femininas, mas, o expoente do amor próprio e exclusivismo directo. Eis em resumo, o conceito do Sr. Gilberto Camara, pobres cartas "individuais e egoísticas", vós, que sois sinceras!

Erroneo é bem o juiso parcial do homem em pressuppor que elle, elle só, possue qualidades e direitos de emitir opiniões que abranjam o seu sexo em geral, e entre ainda na seara alheia, impugnando a liberdade, a razão, o dever que tem - o fragil, o humilde, o incomprehendido de deffender seus sentimentos conspurcados e combater a condição que o inferiorisa.

Manifestando meu modo de pensar em contraposição ao do distincto e illustre antagonista, não restringi o motivo a minha pessoa, pois, mercê de Deus, vivo tranquilla; externei uma attitude em relação aos factos colhidos em profunda observação dentro de diversos Estados brasileiros.

Longo seria o enumerar d'aquelles mais evidentes, mas, para não ir mais longe, remonto-me aqui mesmo, bem perto, a nossa terra, onde o "divorcio" já foi de há muito estabelecido! Admirae-vos? Explico-me; em Fortaleza, notadamente nos subúrbios - areias, propriamento dicto - existem, por centenas, casamentos sem vínculo - Vão as noivas ao padre, e tempos depois, mezes até, voltam-se para o juiz, mudados o homem ou a mulher. Conheço de vista, casos em que, quando um filhinho ainda não deixou o collo materno, tem seu pae substituído, por um outro que lhe não pode ouvir, sem rancor, o 
baluciar infantil... Dizei-me, já vos constou que esta parte de nossa urbe tivesse entrado em equilibrio social?

Affirmo vos, categoricamente, não!

Conhecendo mais de perto nosso povo, em cujo meio actualmente vivo, tenho ouvido, a este respeito, queixas amargas, desesperos profundos, dores sem consolação! Ainda há bem poucos dias, uma d'estas mulheres "contractadas", - é este o termo com que se referem ao casamento civil - dizia-me, ente lagrimas: "Ah! minha dona, si o primeiro desgraçado era ruim, este, por quem o troquei, é mil vezes peior!" Vêde bem, que não procuro salvaguardar interesse particular, conforme conjecturaes.

Quando nos apontam os primeiros cabellos brancos, nessa idade em que a experiências, as desillusões, os desenganos são o cortejo do caminho percorrido, nós, sem parcialidade, impetuosidade ou ardentia, mas, num largo gesto, moderado, sincero e generoso, procuramos alcançar a synthese dos erros accumulados pelas gerações que succedem, e dar-lhes golpe de morte. Que importa que não o consigamos? Batalharmos por um nobre fim e bem confortativo e bem doce.

Agora, que no Universo inteiro intensificam-se sabias leis de protecção aos seres infantis quem os soccorretá?

As uniões que se estabeleciam, votam-n'os aos mais horríveis tormentos!

Foi baseada na triste sorte das creanças, que se me metteu asco, o divórcio. Não são ellas as únicas attingidas pelo infortunio? As que choram sem conforto a separação forçada d'um d'aquelles a quem veneram, a dissolução do lar que tanto amavam, a introducção d'um extranho gerador de ódios, de rancores e apaixonamentos.

Não podereis comprehender, jamais, o immensuravel martyrio d'uma mãe que sente a lucta tácita, inveterada, latente, entre o filho que adora e o novo esposo que estremece!

E' uma magua de todo instante um gemido sem echo, um penar sem desfalecimento!

Convenhamos que uma mulher mude de marido - um novo amor que surge Será por ventura feliz?

L' amour meurt, l' amour refleurir....

Então, trocará maridos como muda de sapatos? Quem poderá fugir a infelicidade? Quem refreiará a desventura? E-se má esposa ou máo marido. 
Como se é sonhador ou assassino. - Está no sangue - é tara. Somos um povo novo, de idéas novas que importa em costumes novos. Não queiramos imitar as sociedades blasées, apodrecidas. Instituamos um Codigo do matrimonio, código de honra, que por força o é, preguemos a recíproca amisade e lealdade entre os cônjuges, visando na união dos mesmos à perfeita harmonia na procreação, educação e protecção aos seres que um dia nos substituirão. Elles representam o futuro de nossa patria. Tão grande, rica, invejada para quem volta os olhos os extrangeiros cubiçosos. Sejamos o expoente maximo da Religião do Dever. Nuvens toldarão, por vezes, os horizontes domésticos. Tudo passa, tudo acaba e na felicidade de nossos filhos irradiem-se e engrandeçam-se os nossos mutuos sacrifícios.

Quem tornou vosso lar bonançoso e abençoado? Seriam, somente, os dotes excelsos da que escolheste entre todas? Não. Foi o reflexo, a herança de vossos maiores; a inteiresa de caracter, a bondade vigilante, a união indestructivel de vossos progenitores. Foi o encanto, transbordante da ternura, da indissolubilidade conjugal de vossos avós. Conheci-os. Passava, em minha juventude, diariamente, à sua porte. Guardo, na retina, como uma paysagem moral suavissima, o quadro que alli me fez sempre alegremente deter... - o rosto suave e austero do velho e insigne jornalista, era a banca do estudo, ora a janella, a espairecer, sempre acompanhado do vulto imponente e respeitavel da dignissima esposa.

Eis vosso mais precioso thesouro! Avaramente, guardae-o; sede o transmissor d'este dom valioso, o mais rico dote que possuirá a vossa Berenice. E, si um dia, vosso coração de pae amantíssimo tiver de entregal-a a um homem, seja àquelle que por ella velará, em toda vida terrena.... Que, por um novo amor legal, do esposo, não volte ella a vossos braços - a face amargurada, a alma envelhecida, o coração torturado.

Adilia de Albuquerque Moraes

3 de Setembro de 1925. (Ceará Illustrado, 07/09/1925, p. 37- 38)

No Jornal A Razão de 19 de maio de 1929 (p. 3), a escritora Adília de Albuquerque Moraes assina a coluna a Razão Literária e apresenta um perfil da escritora Adelaide do Amaral em artigo intitulado Valores despresados. Ao assumir essa seção Adília se dedica ao resgate de escritoras que tiveram um papel importante na literatura, mas que, entretanto, permaneciam esquecidas e apagadas do cenário literário. 
Valores despresados

Quando attendendo à nímia gentileza do illustre Director d'esta folha, assumimos, desde o inicio, a direcção de sua pagina literária, era desejo nosso que fosse ella, em sua môr parte, collaborada pelo elemento feminil.

Matinas varias, impediram-nos de realizar esta aspiração, logo em começo. Há grande desanimno entre as inlectuaes conterraneas: - a indifferença d'uns a ironia de outros, o descaso de terceiros, diminuem e represam os surtos de intelligencia, que bafejados por uma orientação segura, se encamihariam para nobre e proficuos fins.

Foi procurando despertal-as do letargo em que entorpecem os brilhos do espirito, que nos propuzemos a visital-as, a todas, convidando-as a erguerem suas vozes que m]ao podem calar-se a uma epocha em que, de sul a norte do Paiz, nossas irmãse se agremiam para pugnar e vencer.

Após trocarmos idéas com distinctíssimas patricias, já obtiveramos o apoio indispensavel d'estes phenomenos de intelligencia precôce que são Susana de Alencar e Rachel de Queiroz, - encataram-nos as promessas valiosas da renomada escriptora Alba Valdez, da illustre educadora D. Julia Vasconcellos e a cpadjuvação emprehendedora e insinuante da incomparavel Dra. Henriqueta Galeno. Faltavam-nos, porém, outras imprexdindíveis adhesões,e, foi assim, que em uma radiante e clarissima manhã do mez decorrente, batemos a porta d'uma amiga que muito nos honra e interessa.

Surgiu-nos, préstes, a silhueta esbelta de Adelaide Amaral, que, mostrando-se surpresa, convidou-nos a entrar.

Logo à primeira vista, sente-se a impressão de que es está tratando com uma escriptora de raça.... Sua sala alegre e illuminada pelos raios de sol, é guardenica, por toda parte de livros preciosos, e, sua banca de trabalho, ostenta-se ao centro, a dizer que está em continuo conctato com sua assidua possuidora.

Entre risonha e admirada perguntou-nos, pressurosa: Veio despedir-se? Vai partir?

Porque isto? - Já vivo tão esquecida que só uma razão poderosa far-me-ia lembrada.- Não nos esquecemos as amigas - mesmo de longe ellas nos são sempre presentes ao coração. 
Expuzemos o nosso proposito, e foi logo atalhando: commigo não conte, presentemente, para cousa alguma; voluntariamente entreguei-me à obscuridade em que me matenho, há anos, e n'ella persisto e quero conservarme.

- As decepções, as injustiças de que tem sido victimas, crearam-lhe certo ambiente de descrença, de constrangimento em que permanece, como se accupasse ummundo à parte. $\mathrm{O}$ que se lhe não obliterou, foi este innato sentimento de hospitalidade e carinho - característica do nosso povo - e que se irradia, subtilmente, e transparece mesmo nas almas desesperançadas...

Acolheu-nos com uma fidalguia que muito nos penhorou.

Enquanto servia-nos saborissimo café, folheavamos machinalmente, algumas de suas obras, e, ao abrirmos o seu primeiro livro publicado - The essential of English Language - deparamos com na nomeclatura de sua vastissima bagagem literária.

Assim é que tem ella no prêlo - José de Alencar, Iracema, versão ingleza, illustrada pela autora que também é pintora de nomeada,e promptos a publicar - Versão ingleza da Anthologia Nacional de Fausto Barreto e Carlos de laet (prosa).

O problema do feminismo e suas modalidades (conferencia realizada no palacete da Phenix Caixeral em Agosto de 1917) - Adão em ceroulas, trabalho crítico, ao Dr. Carlos de Laert - Intelelctuaes cearenses: Alvaro Fernandes, Antonio Salles, Francisco Prado, Rodolpho Teófilo e outros; Judas à moderna (estudo psycologico) Vinhetas, (artigos avulsos) A força da Escola Normal, prelecção apresentada ao concurso de inglez da Escola Normal. Os Pescadores d Tahyba, de Alvaro Martins (versão francesa e ingleza) - O valle do jaguaribe - Pe. Rodolpho F. da Cunha, (versão ingleza), Anomalias da lingua portuguesa - (Convencionalismo da Gramática). Verdades cruas (estudos sociologicos). José de Alencar - Guarany (versão ingleza). Pinga-fogo (novela). Caricias e Ninho de Cobras, em elaboração (Costumes cearenses).

E, ficamos a pensar - Quanto trabalho despendido, quanto valor despresado! E porque? - Porque o nosso terreno é safaro, esteril e maninho para as sementes que não são seleccionadas... - seleccionadas pela mão dos magnatas, que muitas vezes separam as de melhor apparecia, mas que, por dentro, estão bichadas!... 
A belletrista de quem fallo é diplomada pela escola Normal, pertence a uma familia tradiccional pelo caracter, honradez e indpendencia; desta sahiu um heroe do Abolicionismo que nem precisa mais repetir-lhe o nome e, tem sido, quase toda, devotada à causa da Instrucção.

Ninguem esqueceu ainda, o antigo Collegio das irmãs Amaral, e sete outro ramo mais novo da família, lhe tem seguido esta tendencia especial.

As irmãs Judith e Adelaide Amaral, desde cêdo, se teem dedicado ao ension de línguas a nossas jovens conterraneas e o fazem com grande proficiencia e proveito.

Sempre desajudadas de qualquer conforto official, arrastam uma existencia mediocre, mas altamente digna e quiçá até invejavel!

Realizam sem qualquer auxilia, o nobilissimo ideal porque se bate a mulher moderna - sua inteira independencia pessoal! - Não sei si fomos feril-as em sua modestia. Que nos perdoem - O que tentamos patentear aqui, é o desamor de nossos governantes para as mentalidaes notaveis que, irrompem n'um sorriso feliz es e estiolam n'uma lagrima de amargura... dos que se encontram exilados dentro da terra do berço, e, pela força portentosa com que nos attrae o espirito da propria terra que nos sentimos ficar, sem coragem para deixar de ver os verdes mares bravios, a ponta do Mucuripe e não mais embriagar o olphato com o teu cheiro captoso e perturbador que nos vem da matta perfumada de nossos sertões"

18 de Maio de 1929, Adília de Albuquerque Moraes. (A Razão, 19/05/1929, p. 3)

Adília não apenas traça um perfil da escritora Adelaide Amaral, mas destaca a sua importância para a educação e para a literatura cearense, Pois a considera escritora e tradutora dedicada, comprometida com o estudo dos escritores e das questões políticas e sociais relacionadas à sua terra. Infelizmente não encontramos registro das obras publicadas por Adelaide Amaral e o seu nome não figura em nenhuma obra de estudos literários. Na crônica, a escritora biografada demonstra ressentimento perante as decepções e injustiças sofridas, confirmando o preconceito e as perseguições vivenciadas pelas mulheres que se dedicavam à escrita.

No jornal O Povo, de 4 de julho de 1932, Adília conscientiza suas patrícias sobre a importância do voto feminino. As mulheres deveriam participar da escolha de seus governantes e assim pleitear os seus direitos. 


\section{O VOTO FEMININO}

Adília de Albuquerque Morais

(...)

O decreto 21.076, de 24 de fevereiro de 1932, assinado pelo sr. Getúlio Vargas, com a referenda de seus dignos ministros, integra a mulher brasileira no gozo de sua mais lídima aspiração, concedendo-lhe os sufrágios populares. A princípio, o voto feminino foi estudado, com restrições, para logo em pós ser outorgado com todas as prerrogativas almejadas. Assim é que, na parte primeira do Código Eleitoral vigente, encontra-se: art. $2^{\circ}$ - "É eleitor o cidadão maior de 21 anos, sem distinção de sexo, alistado na forma deste Código", e tão liberal é ratificado este direito, que não exclui a mulher casada com estrangeiro ou mesmo aquelas que tenham vida malsã. Fizeram-se reparos em torno do caso, mas, uma bem inspirada coerência não a modificou. Não é o peso de uma sorte malfadada que possa amortecer os sentimentos nativos e venha inibir aos seres pensantes o direito e dever de interessar-se pelos destinos da nacionalidade.

(...)

Necessitamos dum pensar moço, duma torrente de águas cristalinas que lave as velhas impurezas e deslize, serena, sem tropeços, sem fortes ruídos, sem encachoeirar de conhecidos e usados ditirambos, mas, de frasear firme e decidido, visando um bem comum, duma seiva eficaz, de desprendimentos comedidos, de atuação clara, sem rodeios ou subterfúgios, e, tudo isto, ouso esperar da interferência benéfica da mulher.

Filhas de Iracema, não podeis ficar indiferentes aos dias incertos de nossa pátria. Sois constantes, altivas, sinceras e abnegadas.

Lembrai-vos, que desde esse instante, os nossos conterrâneos têm os olhos voltados para vós.

Avante, pois! (O Povo, 04/07/1932)

\section{CONCLUSÃO}

Isto exposto, concluímos sobre a importância de Adília de Albuquerque, na imprensa cearense do início do século XX, uma vez que apresentamos de forma breve a importância da escritora 
e o seu comprometimento em defender importantes causas em favor da mulher, como a luta pelos direitos civis e sociais e a relevância do voto e da participação feminina nas eleições.

Resgatar a obra da escritora e permitir a sua visibildiade é dar voz a essa militante que participou ativamente das lutas sociais no final do século XIX e início do século XX mas que hoje vive no esquecimento e no silenciamento, dado o apagamento de seu nome nos estudos literários.

\section{REFERÊNCIAS BIBLIOGRÁFICAS}

AZEVEDO, Sânzio de. Literatura Cearense. Fortaleza: Academia Cearense de Letras, 1976. BITTENCOURT, Adalzira. Dicionário bio-bibliográfico de mulheres ilustres, notáveis e intelectuais do Brasil (ilustrado). Volume 1. Rio de Janeiro: Editora Pongetti, 1969.

BRANCO, Lúcia Castello. A escrita mulher. In: BRANCO, Lúcia Castello et BRANDÃO, Ruth Silviano. A mulher escrita. Rio de Janeiro: Casa-Maria/LTC, 1989.

CIXOUS, Hélène. The Laugh of the Medusa. Tradução de Keith Cohen e Paula Cohen. In: Signs, v. 1, nº 4, 1976, p. 875-893.

GOMES \& ZOLIN. Deslocamentos da Escritora Brasileira. Maringá: Eduem, 2011.

HOLLANDA, Heloísa Buarque de \& Lucia Nascimento Araújo. Ensaístas Brasileiras. Rio de Janeiro: Rocco, 1993.

LINHARES, Augusto. Coletânea de Poetas Cearenses. Rio de Janeiro: Editora Minerva Ltda, 1952.

LINHARES, Mário. Poetas esquecidos. Rio de Janeiro: Irmãos Pongetti - Editores, 1938.

MENESES, Antônio Bezerra de. O Ceará e os Cearenses. Fortaleza: Tipografia Minerva, 1906. NOGUEIRA. Joaquim da Costa. Ceará Intellectual (Extracto do “Anno Escolar”). Typographia Escolar. Fortaleza - Ceará, 1910.

SCHUMAHER, Schuma; BRAZIL, Erico Vital. Dicionário mulheres do Brasil: de 1500 até a atualidade. Rio de Janeiro: Zahar, 2000.

WOOLF, Virgínia. Um teto todo seu. Tradução de Vera Ribeiro. Rio de Janeiro: Nova Fronteira, 1985. 